\title{
Clinical Audit on Management of Acute Poststreptococcal Glomerulonephritis in Children Admitted to Assiut University Children Hospital
}

\author{
Marwa A.M. Abuzeid", Ahlam Badawy Ali, Faida M.M. Mostafa \\ Department of Pediatrics, Faculty of Medicine, Assiut University, Assiut, Egypt \\ *Corresponding author: Marwa A.M. Abuzeid, E-mail: Dmarwaa@yahoo.com
}

\begin{abstract}
Background: acute poststreptococcal glomerulonephritis (APSGN) is the most common glomerulopathy among children in our community. Aim: to assess degree of adherence of medical physicians to Assiut University Children Hospital protocol for management of acute poststreptococcal glomerulonephritis. Patients and Methods: fifty eight patients with APSGN admitted to Assiut University Children Hospital were included in this study. The unit's protocol wasfollowed for the management of these cases. Results: evaluation of the studied patients were done perfectly except for $12 \%$ of patients not asked about symptoms suggestive ofhypertension (HTN) and 14\% not checked for oliguria and some laboratory investigations with less importance in diagnosis. Management was perfectly done except for general and supportive measures including daily weighting, calculating fluid input and output, which showed some defect. Putting patients on blood pressure percentiles was not done at all. Conclusion: evaluation of the APSGN patients includes taking proper history of nephritic symptoms and careful clinical examination. Main treatment includes monitoring fluid status and HTN, and proper management to avoid complications. Recommendation: stress on general and supportive measures including weighting patients daily, calculating fluid input and output, checking patients for oliguria, and follow up proper dietary measures especially for hypertensive and hyperkalemic patients. Stress in putting patients on blood pressure levels according to age and height percentiles for accurate detection of HTN.
\end{abstract}

Keywords: Acute poststreptococcal glomerulonehpritis, Assiut University Children Hospital, Audit.

\section{Introduction}

Acute

poststreptococcal

glomerulonephritis (APSGN) is the most common glomerulopathy among children in our community. Typical features of the disease are acute onset of haematuria, edema, facial puffiness and hypertension ${ }^{(\mathbf{1})}$.

Incidence rate for APSGN in developing countries is 24.3 per 100,000 and 2.0 per 100,000 in developed countries. The long-term prognosis of the disease is excellent. The bad prognosis of the disease is due to early mortality and a rapidly progressive clinical course. The overall mortality from APSGN is less than $0.5 \%$. Less than $2 \%$ are complicated by end stage renal diseases ${ }^{(2)}$.

The median age at presentation for APSGN in childhood is between 6 and 8 years old. It rarely occurs before age $2^{(3)}$. It occurs 2-4 weeks following upper respiratory infection and 2-4 weeks following skin infection ${ }^{(4)}$.

Acute nephritic syndrome presenting as edema, hematuria, and hypertension with or without oliguria is the most frequent presentation of APSGN. Approximately 95\% of clinical cases have at least 2 manifestations, and $40 \%$ have the full picture of acute nephritic syndrome. Subclinical cases are 4-10 times more common than symptomatic patients ${ }^{(5)}$.

General symptoms like malaise, weakness, and anorexia may occur in about half of the patients and less complains of nausea and vomiting within a week or so from onset of symptoms ${ }^{\left({ }^{(}\right)}$. APSGN occurs predominantly in males. The clinical course is usually mild, but severe acute renal failure with crescentic formation may occur ${ }^{(7)}$.

Hypertension (HTN) is observed in more than $80 \%$ of patients. The increased peripheral vascular resistance, plasma volume and cardiac output are possible causes of HTN. Some patients present with hypertensive emergency, heart failure or pulmonary edema (8).

The pathogenesis of APSGN is due to multi streptococcal antigens and a patient antibody response with the formation of 
soluble complexes, which cannot be removed by the glomeruli and activate the complement system. At the acute phase of poststreptococcal glomerulonephritis, the level of haemolytic plasma complement (C3) always decreases ${ }^{(9)}$.

Gross examination of the involved kidney shows only punctate hemorrhages throughout the cortex. Microscopically, it shows proliferation and swelling of the mesangial and endothelial cells of the capillary tuft of the glomeruli ${ }^{(\mathbf{1 0})}$.

Microscopic haematuria usually occurs in all patients. Urine examination reveals multiple red blood cells (RBCs) and RBCS casts with evidence of glomerular haematuria. Proteinuria is present in $80 \%$ of patients with APSGN. However massive proteinuria is present in only $4-10 \%$ of patients (11).

Antibody titers to extracellular products of streptococci are positive in more than $95 \%$ of patients with pharyngitis and $80 \%$ of patients with skin infections. The antistreptolysin $\mathrm{O}$ (ASO), antinicotinamide adenine dinucleotidase (anti-NAD), antihyaluronidase (AHase), and anti-DNAse B are commonly positive after pharyngitis, and anti-DNAse B and AHase titers are more often positive following skin infections ${ }^{(12)}$.

Elevated blood urea nitrogen (BUN) and serum creatinine values are usually transient. They occur due to decreased glomerular filtration rate that occurs in the acute phase ${ }^{(\mathbf{1 3})}$.

The C3 levels are decreased in all patients of APSGN, the duration of low values is short. A decreased level for more than 6-8 weeks is unusual ${ }^{(\mathbf{1 4})}$.

There is no specific treatment for poststreptococcal glomerulonephritis. Treatment is focused on relieving symptoms. Antibiotics, such as penicillin, should be used to eradicate any streptococcal bacteria that remain in the body. Antihypertensive drugs and diuretics may be needed to control edema and hypertension ${ }^{(\mathbf{1 5})}$. The most effective treatment of hypertension and edema in APSGN is loop or thiazide diuretics. Angiotensin-converting enzyme inhibitors or angiotensin receptor blockers may be effective in control of hypertension but carry the risk of hyperkalemia and transient impairment of kidney function ${ }^{(16)}$.
Corticosteroids and other antiinflammatory drugs are generally not effective. Salt limitation in the diet may be needed to control edema and hypertension ${ }^{(17)}$.

\section{Aim of the study:}

To assess degree of adherence of medical physicians to Assiut University Children Hospital protocol for management of acute poststreptococcal glomerulonephritis.

\section{Patients and Methods}

Study design: This is an audit, descriptive study.

Study setting and time: The study included all cases with APSGN admitted to Assiut University Children Hospital from $1^{\text {st }}$ of October, 2016 to $30^{\text {th }}$ of September, 2017.

Study population: Fifty eight patients with APSGN were participated in this study. Their ages were ranged from 3 to 15 years with mean age 7 years, 34 males and 24 females.

Inclusion criteria: All patients with APSGN admitted to Assiut University Children Hospital.

Exclusion criteria: All patients admitted to Assiut University Children Hospital with APSGN complicated by nephrotic syndrome, renal failure, pulmonary edema and encephalopathy.

Ethical statement: The study protocol was approved by the Ethical Committee of Assiut Faculty of Medicine. Any data taken from the patient was dealt within confidential manner.

All patients were subjected to full history taking and relevant laboratory investigations.

Data were collected about evaluation of general and supportive measures done in the studied patients including (advising bed rest, weighting daily, monitoring fluid input and output and following proper dietary measures). Also, data were collected about medical treatment of those patients including eradication of streptococcal infection, putting patients on blood pressure levels according to age and height percentiles, medical treatment 
of HTN with antihypertensive drugs including (diuretics, calcium channel blockers and $\mathrm{B}$ blockers).

The protocol that was used in the management of patients with APSGN admitted to Assiut University Children Hospital was according to modified South African Guidelines ${ }^{(\mathbf{1 8})}$.
Statistical analysis: Data were analyzed using the statistical package for social sciences (SPSS Inc., Chicago, Illinois, USA) version 20.0. Quantitative data were expressed as mean \pm standard deviation (SD). Qualitative data were expressed as frequency and percentage.

\section{Results}

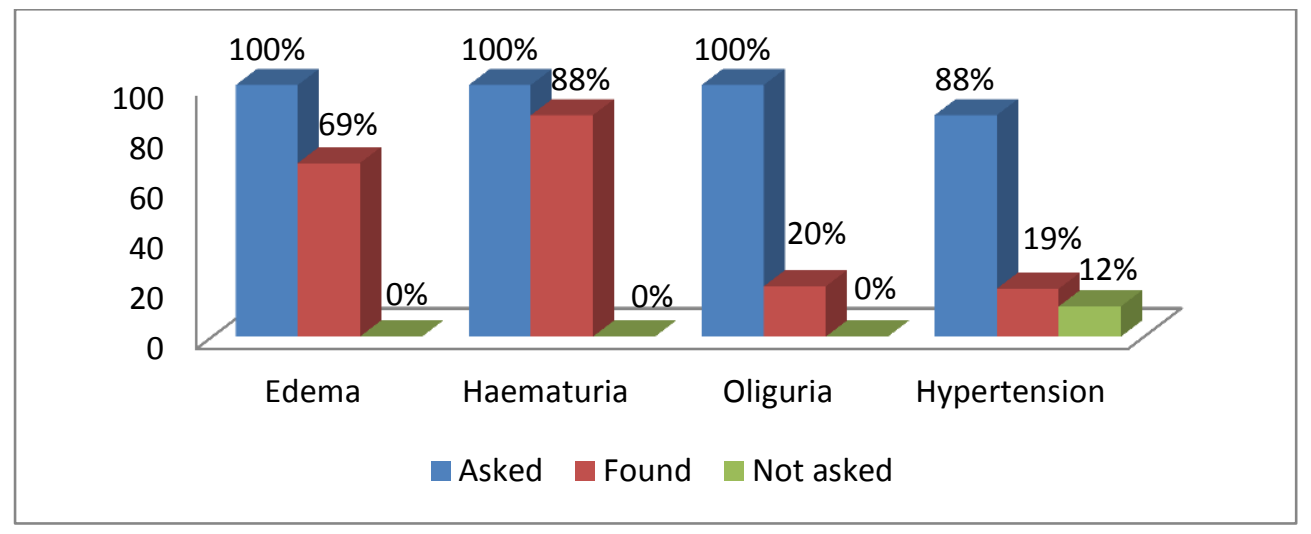

Figure (1): Frequency of recorded data about history of edema, red urine, oliguria and symptoms suggestive of hypertension

Figure (1) shows that all cases were asked about edema, red urine and oliguria. And $12 \%$ of cases were not asked about symptoms suggestive of HTN. The most presenting complaint in our study was haematuria $88 \%$, followed by edema $69 \%$ and oliguria $20 \%$. History suggestive of HTN was found in only $19 \%$ of cases.

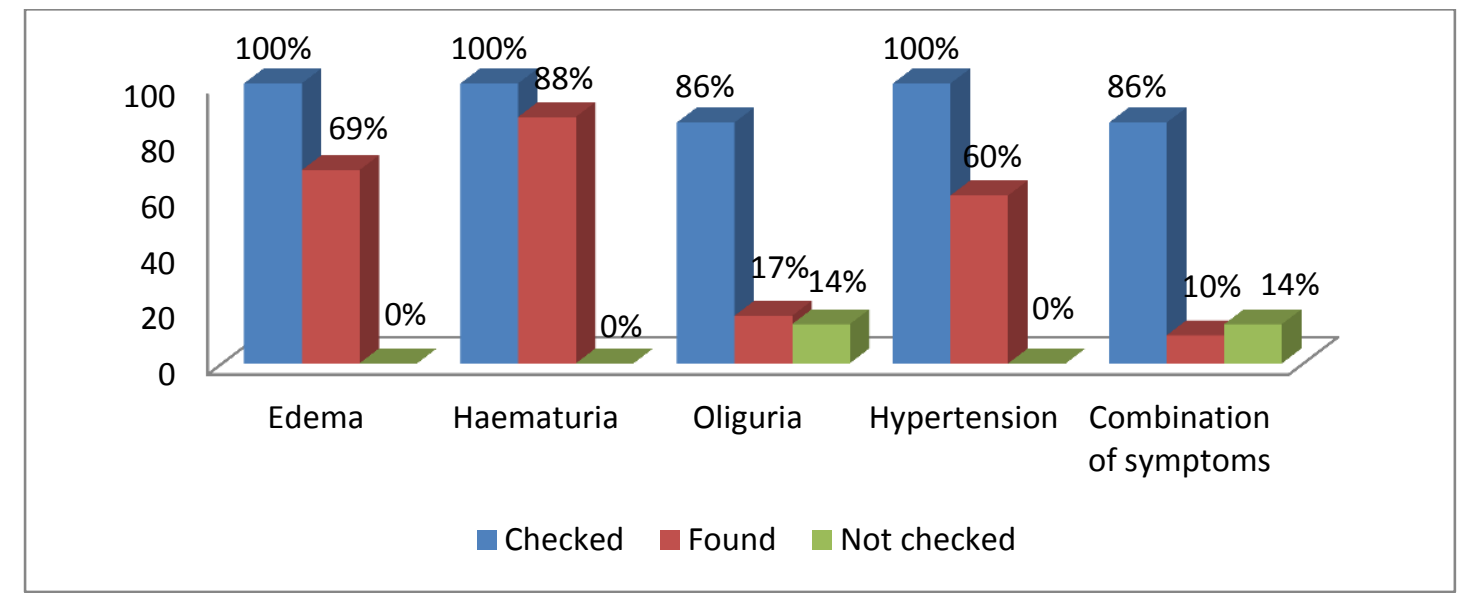

Figure (2): Frequency of recorded data about cases checked for edema, haematuria, oliguria and hypertension by examination

Figure (2) shows that all cases were checked for edema, haematuria, oliguria and hypertension except for $14 \%$ of cases were not checked for oliguria. Haematuria was found in $88 \%$ of cases, edema in $69 \%$ of cases, HTN in $60 \%$ of cases and oliguria in $17 \%$ of cases. HTN was found in 35 cases, 24 of them were asymptomatic. 
Table (1): Frequency of recorded data about serum biochemistry, CBC, ABG, estimation of ASOT, complement test, and urine analysis done in the studied patients

\begin{tabular}{|c|c|c|c|}
\hline \multirow{2}{*}{ Investigations } & Cases & Done & Not done \\
\hline \multirow{2}{*}{ Sodium } & Number & $58 / 58$ & $0 / 58$ \\
\cline { 2 - 4 } & Percentage & $100 \%$ & $0 \%$ \\
\hline \multirow{2}{*}{ Potassium } & Number & $58 / 58$ & $0 / 58$ \\
\cline { 2 - 4 } & Percentage & $100 \%$ & $0 \%$ \\
\hline \multirow{2}{*}{ Chloride } & Number & $3 / 58$ & $55 / 58$ \\
\cline { 2 - 4 } & Percentage & $5 \%$ & $95 \%$ \\
\hline \multirow{2}{*}{ Urea } & Number & $58 / 58$ & $0 / 58$ \\
\cline { 2 - 4 } & Percentage & $100 \%$ & $0 \%$ \\
\hline \multirow{2}{*}{ Creatinine } & Number & $58 / 58$ & $0 / 58$ \\
\cline { 2 - 4 } & Percentage & $100 \%$ & $0 \%$ \\
\hline \multirow{2}{*}{ Hb } & Number & $58 / 58$ & $0 / 58$ \\
\cline { 2 - 4 } & Percentage & $100 \%$ & $0 \%$ \\
\hline \multirow{2}{*}{ WBCs } & Number & $58 / 58$ & $0 / 58$ \\
\cline { 2 - 4 } & Percentage & $100 \%$ & $0 \%$ \\
\hline \multirow{2}{*}{ ABG } & Number & $19 / 58$ & $39 / 58$ \\
\cline { 2 - 4 } & Percentage & $33 \%$ & $67 \%$ \\
\hline \multirow{2}{*}{ ASOT } & Number & $58 / 58$ & $0 / 58$ \\
\cline { 2 - 4 } & Percentage & $100 \%$ & $0 \%$ \\
\hline \multirow{2}{*}{ C3 } & Number & $58 / 58$ & $0 / 58$ \\
\cline { 2 - 4 } & Percentage & $100 \%$ & $0 \%$ \\
\hline \multirow{2}{*}{$\mathrm{C} 4$} & Number & $58 / 58$ & $0 / 58$ \\
\cline { 2 - 4 } & Percentage & $100 \%$ & $0 \%$ \\
\hline \multirow{2}{*}{ Urine analysis } & Number & $58 / 58$ & $0 / 58$ \\
\cline { 2 - 4 } & Percentage & $100 \%$ & $0 \%$ \\
\hline & & & \\
\hline
\end{tabular}

Table (1) shows that urine analysis, ASOT, complement test, Urea and creatinine and serum electrolytes ( $\mathrm{Na}$ and $\mathrm{K}$ ) were done in $100 \%$ of cases. Meanwhile, serum chloride was done in only 3 cases and arterial blood gas (ABG) was done in $33 \%$ of cases.

Table (2): Evaluation of general and supportive measures done in the studied patients

\begin{tabular}{|c|c|c|c|}
\hline Recommendation & Cases & Done & Not done \\
\hline \multirow{2}{*}{ Bed rest } & Number & $58 / 58$ & $0 / 58$ \\
\hline & Percentage & $100 \%$ & $0 \%$ \\
\hline \multirow{2}{*}{$\begin{array}{c}\text { Monitor fluid balance : } \\
\text { Daily weight }\end{array}$} & Number & $34 / 58$ & $24 / 58$ \\
\hline & Percentage & $59 \%$ & $41 \%$ \\
\hline \multirow{2}{*}{ Fluid intake } & Number & $38 / 58$ & $20 / 58$ \\
\hline & Percentage & $66 \%$ & $34 \%$ \\
\hline \multirow{2}{*}{ Urine out put } & Number & $50 / 58$ & $8 / 58$ \\
\hline & Percentage & $86 \%$ & $14 \%$ \\
\hline \multirow{2}{*}{ Restrict sodium intake } & Number & $43 / 58$ & $15 / 58$ \\
\hline & Percentage & $74 \%$ & $26 \%$ \\
\hline \multirow{2}{*}{$\begin{array}{l}\text { Restrict potassium till lab } \\
\text { results }\end{array}$} & Number & $0 / 58$ & $58 / 58$ \\
\hline & Percentage & $0 \%$ & $100 \%$ \\
\hline \multirow{2}{*}{$\begin{array}{l}\text { Restrict proteins to } 0.5 \\
\mathrm{gm} / \mathrm{kg} / \text { day }\end{array}$} & Number & $0 / 58$ & $58 / 58$ \\
\hline & Percentage & $0 \%$ & $100 \%$ \\
\hline
\end{tabular}


Table (2) shows evaluation of general and supportive measures done in the studied patients: bed rest was advised in $100 \%$ of cases, while daily weight was done in 59\% of them. Monitoring fluid intake was done in $66 \%$ of cases and monitoring urine output was done in $86 \%$ of them. Na restriction was done in $74 \%$ of cases, but $\mathrm{K}$ restriction was not done in all patients including hyperkalemic patients. Protein restriction to $0.5 \mathrm{gm} / \mathrm{kg} / \mathrm{day}$ was not also done in the studied patients.

Table (3): Frequency of recorded data about eradication of streptococci in the studied patients

\begin{tabular}{|l|c|c|c|}
\hline \multicolumn{1}{|c|}{ Treatment } & Cases & $\begin{array}{c}\text { Advised } \\
\text { properly }\end{array}$ & $\begin{array}{c}\text { Not advised } \\
\text { properly }\end{array}$ \\
\hline $\begin{array}{l}\text { Amoxicillin +Clavulanic acid: } \\
\text { Oral 25-50mg/kg/day } \\
\begin{array}{l}\text { In 2 divided doses } \\
\text { For 10 days }\end{array}\end{array}$ & Number & $52 / 58$ & $6 / 58$ \\
\cline { 2 - 4 } & Percentage & $90 \%$ & $10 \%$ \\
\hline
\end{tabular}

Table (3) shows that amoxicillin-clavulanic acid was prescribed in proper dose and duration in $90 \%$ of cases.

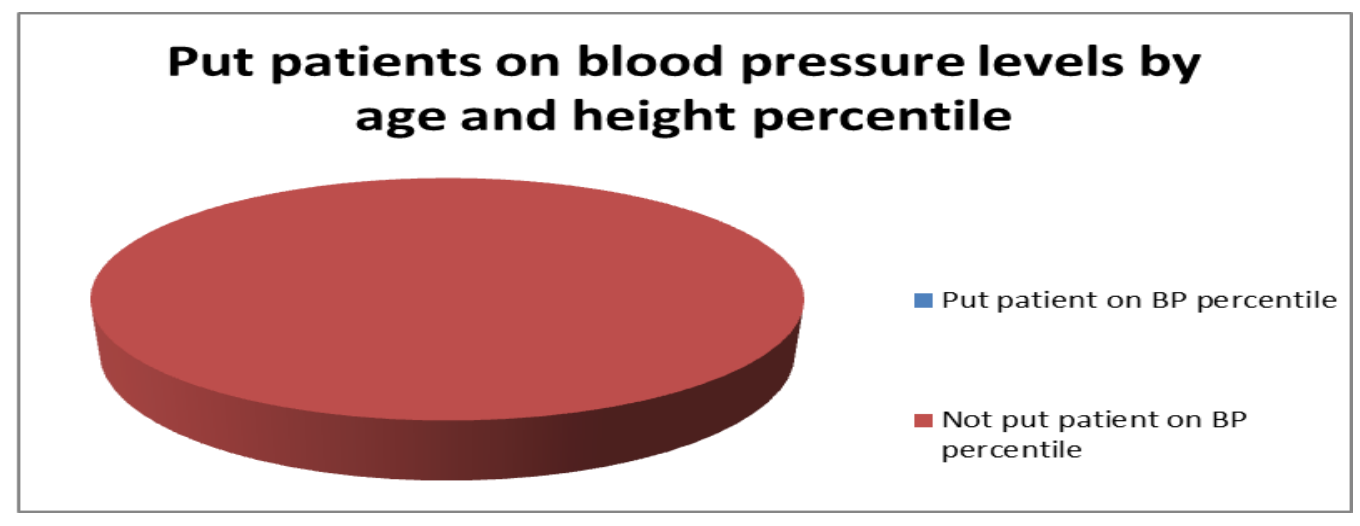

Figure (3): Frequency of recorded data about putting patients on blood pressure levels according to age and height percentiles

Figure (3) shows that all cases were not put on blood pressure levels according to age and height percentiles.

Table (4): Frequency of recorded data about treatment of HTN in the studied patients

\begin{tabular}{|c|c|c|c|}
\hline Treatment & Cases & $\begin{array}{l}\text { Advised } \\
\text { properly }\end{array}$ & $\begin{array}{c}\text { Not advised } \\
\text { properly }\end{array}$ \\
\hline \multirow{2}{*}{$\begin{array}{l}\text { Initially: } \\
\text { Furosemide: IV } 1-2 \mathrm{mg} / \mathrm{kg} / \mathrm{dose} \text {, slowly over } 5 \text { minutes, } \\
\text { Maximum } 5 \mathrm{mg} / \mathrm{kg} / \mathrm{dose} \text {, Repeated according to fluid overload }\end{array}$} & Number & $30 / 35$ & $5 / 35$ \\
\hline & Percentage & $86 \%$ & $14 \%$ \\
\hline \multirow{2}{*}{$\begin{array}{l}\text { Nifedipine added when there was no response to furosemide: } \\
0.25-0.5 \mathrm{mg} / \mathrm{kg} / \mathrm{dose} \text { sublingual, } \\
\text { Can be repeated after } 30-60 \text { minutes }\end{array}$} & Number & $2 / 2$ & $0 / 2$ \\
\hline & Percentage & $100 \%$ & $0 \%$ \\
\hline \multirow{2}{*}{$\begin{array}{l}\text { Once blood pressure was normalized: } \\
\text { Captopril: } 0.5-2 \mathrm{mg} / \mathrm{kg} / \mathrm{day} \\
\text { Oral every } 8 \text { hours }\end{array}$} & Number & $35 / 35$ & $0 / 35$ \\
\hline & Percentage & $100 \%$ & $0 \%$ \\
\hline \multirow{2}{*}{$\begin{array}{l}\text { Nifedipine added when there was no response: } \\
0.25-0.5 \mathrm{mg} / \mathrm{kg} / \text { dose Oral every } 8 \text { hours }\end{array}$} & Number & $6 / 6$ & $0 / 6$ \\
\hline & Percentage & $100 \%$ & $0 \%$ \\
\hline \multirow{2}{*}{$\begin{array}{l}\text { Atenolol added when there was no response: } \\
0.5-1 \mathrm{mg} / \mathrm{kg} / \text { dose once } / \text { day } \\
\text { Maximum dose: } 2 \mathrm{mg} / \mathrm{kg} / \text { day. }\end{array}$} & Number & $0 / 35$ & $35 / 35$ \\
\hline & Percentage & $0 \%$ & $100 \%$ \\
\hline
\end{tabular}


Table (4) shows that number of patients with HTN in our study was 35 out of 58 cases and furosemide was used as an initial treatment of HTN in 30 cases $86 \%$ of them, and two cases were not controlled by furosemide alone and sublingual nifedipine was used. Regarding oral treatment of HTN once blood pressure was normalized: captopril was used in $100 \%$ of cases presented by HTN, six of them were not controlled by captopril alone and oral nifidipine was added. Atenolol was not used in $100 \%$ of cases.

\section{Discussion}

APSGN is a disease characterized by the sudden appearance of edema, haematuria, proteinuria, and hypertension. It is a representative disease of acute nephritic syndrome $^{(14)}$.

In the present study we tried to highlight on management of APSGN in Assiut University Children Hospital and the degree of agreement of the management with South African Guidelines for management of APSGN $^{(18)}$.

All patients' ages in the present study were recorded and we noticed that APSGN was more presented from age of 3 years to 15 years, and most of them around the age of 4-10 years, this is keeping with Matthew et al. ${ }^{(3)}$.

In this study the most common presenting complaint that enforces the APSGN patients to seek medical advice and accept hospital admission was haematuria in $88 \%$ of cases, followed by edema in $69 \%$ of patients that was comparable to Sung et al. ${ }^{(\mathbf{1 9})}$.

In the present study, all patients were evaluated for haematuria, edema, and HTN. There is defect in checking for oliguria as urine output was not calculated in $13 \%$ of cases. Full picture of nephritic syndrome (haematuria, edema, oliguria and HTN) was found in only $10 \%$ of cases, and this is against Christy et al. ${ }^{(20)}$.

Urine analysis, ASOT, complement test, $\mathrm{CBC}$, urea and creatinine and serum electrolytes ( $\mathrm{Na}$ and $\mathrm{K}$ ) were done in $100 \%$ of cases, and these results are agreement with Geetha ${ }^{(12)}$. The present study showed some defect in investigations that have least role in the diagnosis of APSGN as ABG that was done in $33 \%$ of cases when indicated and serum chloride that was done in only 3 cases.
For eradication of streptococci, amoxicillin-clavulanic acid was prescribed in proper dose and duration in $90 \%$ of patients.

Our study showed that bed rest was advised in $100 \%$ of cases, but there was defect in daily weight as it was done in only $59 \%$ of patients. Also showing defect in monitoring fluid intake as it was done in $66 \%$ of cases, monitoring urine output that was done in $86 \%$ of them, and $14 \%$ of patients not checked for oliguria. Regarding dietary measures taken for the studied patients, Na restriction was done in $74 \%$ of cases. But there was defect in $\mathrm{K}$ restriction that was not done at all in all patients including hyperkalemic patients making them liable for complications. Also protein restriction to $0.5 \mathrm{gm} / \mathrm{kg} / \mathrm{day}$ was not done at all in the studied patients, and this is against Jeena et al. $^{(\mathbf{1 8})}$.

Our study revealed that management of HTN was done efficiently except for putting patients on blood pressure levels according to age and height percentiles for accurate detection of HTN, that was against Jeena $\boldsymbol{e t}$ al. (18). HTN was found in 35 cases out of 58 . And furosemide was used as an initial treatment of HTN in $86 \%$ of cases, while nifidipine was used in only two cases that were not controlled by furosemide alone. Captopril was given to all cases presented by HTN, six of them were not controlled by captopril alone and oral nifidipine was added.

\section{Conclusion}

Evaluation of APSGN patients includes taking proper history of nephritic symptoms including edema, hematuria, oliguria and hypertension and careful clinical examination. Main treatment includes monitoring of fluid status and of HTN and proper management to avoid complications.

\section{Recommendation}

Stress on general and supportive measures including weighting patients daily, calculating fluid input and output, checking patients for oliguria, and follow up proper dietary measures especially for hypertensive and hyperkalemic patients. Stress in putting patients on blood pressure levels according to age and height percentiles for accurate detection of HTN and strictly follow the guidelines in the diagnosis of APSGN and in the starting of treatment. 


\section{References}

1. Tasic $V$ and Polenakovic $M$ (2014): Thrombocytopenia during the course of acute poststreptococcal glomerulonephritis. The Turkish Journal of Pediatrics, 45(2):148-51.

2. World Health Organization (2005): The Current Evidence for the Burden of Group A Streptococcal Diseases, Acute poststreptococcal glomerulonephritis- Mortality and complications. Available at: http://apps.who.int/iris/bitstream/handle/10665 /69063/WHO_FCH_CAH_05.07.pdf

3. Matthew E, Ault B, Jones B, Chesney R, Wyatt R (2011): Post streptococcal acute glomerulonephritis in children: clinical features and pathogenesis. Pediatric Nephrology, 26:165-180.

4. Iturbe BI (2016): Post streptococcal glomerulonephritis, clinical and serological characteristics. In: Streptococcus pyogenes: Basic Biology to Clinical Manifestations. University of Oklahoma Health Sciences Center.

5. Roy $R$ and Laila $K$ (2014): Acute poststreptococcal glomerulonephritis in children $-\mathrm{A}$ review. Bangladesh Journal of Child Health, 38(1): 32-39.

6. Singh G (2011): Post infectious glomerulopathies. In: An update on glomerulopathies - Clinical and Treatment Aspects Book, Elsevier Biobase.

7. El-Tigani A, Babikir A, El Al Assad S, Abdelrahim M (2014): Prognosis of acute post-streptococcal glomerulonephritis in Sudanese children. Arab Journal of Nephrology and Transplantation, 7(2):103-7.

8. Avner E, Harmon W, Niaudet N (2010): Clinical manifestations of acute post streptococcal glomerulonephritis, glomerular disease. In: Pediatric Nephrology, $6^{\text {th }}$ edition, Springer-Verlag New, York, LLC.

9. Qian GL, Huang L, Mao JH, Liu AM (2014): Acute Poststreptococcal Glomerulonephritis with Normal Range Complement C3 Level: Three Case Reports. Hong Kong Journal of Pediatrics, 19(3):188191.

10. McAninch J, Lue T, Lee BK, Vincenti FG (2013): Diagnosis of Medical Renal Diseases. In: Smith \& Tanagho's General Urology, 18 edition, Chapter 33, The McGraw-Hill Company, Inc.

11. Elzouki AA, Harfi HA, Nazer H, Stapleton FB, Whitley RJ (2012): Post streptococcal acute glomerulonephritis,
Kidney and Urinary Tract Disorders. In: Text Book of Clinical Pediatrics, $2^{\text {nd }}$ edition, Springer, Berlin, Heidelberg.

12. Geetha D (2012): Post streptococcal glomerulonephritis. Available at: http://emedicine.medscape.com/article/240337 -overview

13. Jennette C, Olson GL, Shwartz MM, Selva FG (2007): Acute post infectious glomerulonephritis and glomerulonephritis caused by persistent bacterial infections. In: Heptinstall's Pathology of the Kidney, $6^{\text {th }}$ edition, Volume 1, Lippincott Williams \& Wilkins.

14. Bhimma $R$ (2014): Acute post streptococcal glomerulonephritis treatment and management. Available at: https://emedicine.medscape.com/article/98068 5-treatment

15. Young AS, Ingulli E (2008): Acute poststreptococcal glomerulonephritis: an update. Current Opinion Pediatrics Journal, 20(2):157-62.

16. Van De Voorde RG (2015): Acute poststreptococcal glomerulonephritis: the most common acute glomerulonephritis. Pediatric Revolution Journal, 36(1):3-12.

17. Taal WM, Chertow GM, Marsden PA, Skorecki K, Alan S LY, Brenner BM (2015): Primary glomerular disease. In: Brenner and Rector's The Kidney, $10^{\text {th }}$ edition, Elsevier-Saunders and Mosby.

18. Jeena PM, Bamford L, Hoek B, Boon GP, Ndondo A, Parbhoo K, Schaaf HS, Sutton C, Biljon IV (2014): Acute poststreptococcal glomerulonephritis. Chapter 6, Renal Conditions, Standard Treatment Guidelines and Essential Medicines List for South Africa, $5^{\text {th }}$ edition, The National Department of Health, Pretoria, South Africa.

19. Sung H, Lim CH, Shin M, Kim B, Song H, Choi E, Chang Y (2007): A Case of PostStreptococcal Glomerulonephritis with Diffuse Alveolar Hemorrhage. J Korean Med Science, 22(6): 1074-1078.

20. Christy C, Lynn C J, Kaczorowskl G (2007): Diseases and disorders, acute poststreptococcal glomerulonephritis. In: Pediatric Clinical Advisor: Instant Diagnosis and Treatment, $2^{\text {nd }}$ edition, Elsevier Health Sciences. 